\title{
Effects of Thymus vulgaris L., Cinnamomum verum J.Presl and Cymbopogon nardus (L.) Rendle Essential Oils in the Endotoxin-induced Acute Airway Inflammation Mouse Model
}

\author{
Eszter Csikós ${ }^{1,+}{ }^{\dagger}$ Kata Csekő ${ }^{2,3,+}{ }^{\dagger}$ Amir Reza Ashraf ${ }^{1}$, Ágnes Kemény ${ }^{2,3,4}$, László Kereskai ${ }^{5}$, \\ Béla Kocsis ${ }^{6}$, Andrea Böszörményi ${ }^{7}$, Zsuzsanna Helyes ${ }^{2,3,8}$ and Györgyi Horváth ${ }^{1, * \mathbb{D}}$ \\ 1 Department of Pharmacognosy, Faculty of Pharmacy, University of Pécs, H-7624 Pécs, Hungary; \\ csikos.eszter@gytk.pte.hu (E.C.); amirreza@gmail.com (A.R.A.) \\ 2 Department of Pharmacology and Pharmacotherapy, Medical School, University of Pécs, \\ H-7624 Pécs, Hungary; csekoe.kata@gmail.com (K.C.); agnes.kemeny@aok.pte.hu (Á.K.); \\ zsuzsanna.helyes@aok.pte.hu (Z.H.) \\ 3 Szentágothai Research Centre, University of Pécs, H-7624 Pécs, Hungary \\ 4 Department of Medical Biology and Central Electron Microscope Laboratory, Medical School, \\ University of Pécs, H-7624 Pécs, Hungary \\ 5 Department of Pathology, Medical School, University of Pécs, H-7624 Pécs, Hungary; kereskai.laszlo@pte.hu \\ 6 Department of Medical Microbiology and Immunology, Medical School, University of Pécs, \\ H-7624 Pécs, Hungary; kocsis.bela@pte.hu \\ 7 Department of Pharmacognosy, Faculty of Pharmacy, Semmelweis University, H-1085 Budapest, Hungary; \\ boszormenyi.andrea@pharma.semmelweis-univ.hu \\ 8 PharmInVivo Ltd., H-7629 Pécs, Hungary \\ * Correspondence: horvath.gyorgyi@gytk.pte.hu; Tel.: +36-72-503650-28823 \\ + These authors contributed equally to this work.
}

Academic Editors: Giuseppe Caruso, Nicolò Musso and Claudia Giuseppina Fresta Received: 20 July 2020; Accepted: 30 July 2020; Published: 4 August 2020

check for updates

\begin{abstract}
Thyme (TO), cinnamon (CO), and Ceylon type lemongrass (LO) essential oils (EOs) are commonly used for inhalation. However, their effects and mechanisms on inflammatory processes are not well-documented, and the number of in vivo data that would be important to determine their potential benefits or risks is low. Therefore, we analyzed the chemical composition and investigated the activity of $\mathrm{TO}, \mathrm{CO}$, and $\mathrm{LO}$ on airway functions and inflammatory parameters in an acute pneumonitis mouse model. The components of commercially available EOs were measured by gas chromatography-mass spectrometry. Airway inflammation was induced by intratracheal endotoxin administration in mice. EOs were inhaled during the experiments. Airway function and hyperresponsiveness were determined by unrestrained whole-body plethysmography on conscious animals. Myeloperoxidase (MPO) activity was measured by spectrophotometry from lung tissue homogenates, from which semiquantitative histopathological scores were assessed. The main components of TO, CO, and $\mathrm{LO}$ were thymol, cinnamaldehyde, and citronellal, respectively. We provide here the first evidence that $\mathrm{TO}$ and $\mathrm{CO}$ reduce inflammatory airway hyperresponsiveness and certain cellular inflammatory parameters, so they can potentially be considered as adjuvant treatments in respiratory inflammatory conditions. In contrast, Ceylon type LO inhalation might have an irritant effect (e.g., increased airway hyperresponsiveness and MPO activity) on the inflamed airways, and therefore should be avoided.
\end{abstract}

Keywords: thyme; lemongrass; cinnamon; essential oil; endotoxin; airway inflammation; mouse model; airway hyperresponsiveness; myeloperoxidase activity; perivascular edema 


\section{Introduction}

Essential oils (EOs) are made up of secondary metabolites by plants. They are liquid mixtures of various compounds (such as terpenoids and phenylpropane derivates) that evaporate at room temperature. Their most common extraction method is distillation. Due to their characteristic aroma and biological effects, EOs are commonly used for different purposes in the fields of aromatherapy, food preservation, plant pathology and medical microbiology. The application of EOs is increasing among patients as a single or adjuvant treatment for respiratory diseases and inflammations based on traditional use and empirical evidence.

Inflammatory lung diseases affect a large population at every age worldwide, and they also appear on the list of the top 10 causes of death [1]. These diseases are associated with acute or chronic inflammation and deteriorate the patients' quality of life.

The advantages of EOs are that they can easily reach the respiratory tract via inhalation due to their volatility, and because of their complex composition they can exert multiple actions through the modification of lipoxygenase, cyclooxygenase and inducible nitric oxide synthase function as well as the inhibition of the inflammatory mediator production [2,3]. Recent studies have proved the anti-inflammatory effects of eucalyptus and lavender EOs, 1,8-cineole (eucalyptol), and menthol [2,4-6].

Thyme (TO), cinnamon (CO) and lemongrass (LO) EOs are commonly used via inhalation. Their components have been shown to reduce inflammatory cytokine production and some inflammatory parameters [7-15]. However, the results of previous studies are poorly comparable and not conclusive, because the studies used EOs of different sources, purity and compositions, mainly certain isolated components are studied, moreover, the experimental paradigms, investigated parameters and the outcomes greatly differ from each other. Furthermore, there are only few in vivo data and airway function results are even more scarcely available, which would be important to determine their potential clinical benefits and risks, particularly under inflammatory conditions.

TO is extracted from the fresh flowering aerial parts of Thymus vulgaris L. (Lamiaceae) and other Thymus species via steam distillation. Thymus vulgaris has several chemotypes containing different main components such as thymol, carvacrol, linalool, and geraniol. The most prevalent use of TO is by inhalation as an expectorant in bronchitis and common cold [16,17].

We used the EO of Cinnamomum verum J.S. Presl. (Lauraceae) as CO, isolated by steam distillation from the bark of the shoots with trans-cinnamaldehyde, as the main component. In medieval times, $\mathrm{CO}$ was used against frontal sinusitis and common cold, but nowadays, it is more commonly used for the treatment of gastrointestinal problems [18].

LO is obtained by steam distillation from the fresh or partially dried aerial parts of Cymbopogon species. We used the EO of Cymbopogon nardus (L.) Rendle (Poaceae, Ceylon type). Characteristic components are citronellal, geraniol, citronellol, limonene, citronellyl acetate, geranyl acetate and neral. The treatment of common cold is among the traditional uses of LO [19,20].

The endotoxin (lipopolysaccharide: LPS)-induced acute airway inflammation mouse model is the most commonly used, well-reproducible mechanism model for the study of EOs in acute respiratory inflammation $[10,13,15,21]$. LPS is a compound of the Gram-negative bacterial cell wall that causes interstitial pneumonitis and acute respiratory obstruction with a well-defined mechanism by activating Toll-like receptor-4 on macrophages, resulting in the release of several inflammatory mediators and consequent neutrophil activation after intranasal or intratracheal administration [22].

Here, we analyzed the chemical composition of $\mathrm{TO}, \mathrm{CO}$ and $\mathrm{LO}$, and investigated their effects on airway functions and inflammatory parameters in the endotoxin-induced acute pneumonitis mouse model, which is a characterized pathophysiological mechanism model relevant to several conditions of human lung inflammation. 


\section{Results}

\subsection{Chemical Analysis of EOs}

Chemical analysis of EOs was conducted using gas chromatography with a flame-ionization detector (GC-FID) and GC-MS. The main components of TO were thymol (46.3\%) and $p$-cymene (22.1\%); cinnamaldehyde was the main component $(74.0 \%)$ in $\mathrm{CO}$; whereas citronellal $(36.2 \%)$ and geraniol $(25.3 \%)$ were present in the highest concentrations in LO (Table 1). Other significant identified compounds included 1,8-cineole $(9.8 \%)$, linalool (5.1\%), and carvacrol $(3.2 \%)$ in TO; cinnamyl acetate $(5.3 \%)$ and linalool (3.9\%) in CO; and citronellol (13.6\%), limonene (3.6\%) in LO.

Table 1. The chemical composition of the investigated essential oils in percentage from 3 parallel measurements (main components in bold).

\begin{tabular}{|c|c|c|c|c|}
\hline Compound & $\begin{array}{c}\mathbf{t R} \\
(\mathrm{min})\end{array}$ & $\begin{array}{c}\text { Thyme } \\
(\%)\end{array}$ & $\begin{array}{c}\text { Cinnamon } \\
(\%)\end{array}$ & $\begin{array}{c}\text { Lemongrass } \\
(\%)\end{array}$ \\
\hline$\alpha$-Pinene & 5.8 & 0.9 & 0.9 & - \\
\hline Camphene & 6.1 & 0.9 & - & - \\
\hline$\beta$-Myrcene & 6.3 & 0.7 & - & \\
\hline$\beta$-Pinene & 6.7 & 1.4 & 0.5 & - \\
\hline$\alpha$-Terpinene & 7.0 & 2.2 & - & - \\
\hline$o$-Cymene & 7.0 & 0.3 & & \\
\hline$p$-Cymene & 7.4 & 22.1 & 1.2 & - \\
\hline Limonene & 7.5 & - & 1.4 & 3.6 \\
\hline 1,8-Cineole & 7.9 & 9.8 & 2.1 & - \\
\hline$\gamma$-Terpinene & 8.6 & 0.3 & - & - \\
\hline Linalool & 10.2 & 5.1 & 3.9 & - \\
\hline Citronellal & 10.4 & - & - & 36.2 \\
\hline Terpinen-4-ol & 11.7 & 0.6 & - & - \\
\hline$\alpha$-Terpineole & 11.8 & 0.2 & 1.6 & - \\
\hline Citronellol & 11.9 & - & - & 13.6 \\
\hline Camphore & 12.1 & 0.5 & - & - \\
\hline Neral & 12.2 & - & - & 1.0 \\
\hline Geraniol & 12.4 & - & - & 25.3 \\
\hline Borneol & 12.4 & 1.5 & - & - \\
\hline Geranial & 12.8 & - & - & 2.2 \\
\hline Cinnamaldehyde & 12.9 & - & 74.0 & - \\
\hline Anethol & 13.1 & - & 4.5 & - \\
\hline Thymol & 13.2 & 46.3 & - & - \\
\hline Carvacrol & 13.3 & 3.2 & - & - \\
\hline Citronellyl acetate & 14.1 & - & - & 2.3 \\
\hline Eugenol & 14.2 & - & 2.7 & - \\
\hline Geranyl acetate & 14.5 & - & - & 2.6 \\
\hline$\beta$-Elemene & 14.7 & 0.4 & - & 2.9 \\
\hline$\beta$-Caryophyllene & 15.4 & 2.5 & 1.7 & - \\
\hline$\alpha$-Humulene & 15.6 & 0.5 & - & - \\
\hline$\beta$-Cubebene & 15.7 & - & - & 2.9 \\
\hline Cinnamyl acetate & 15.8 & - & 5.3 & - \\
\hline$\alpha$-Muurolene & 16.6 & - & - & 1.6 \\
\hline$\beta$-Cadinene & 16.9 & - & - & 3.2 \\
\hline Elemol & 17.4 & - & - & 2.4 \\
\hline Caryophyllene oxide & 18.0 & 0.5 & - & - \\
\hline Eudesmol & 18.3 & - & - & 2.3 \\
\hline Total & & 99.5 & 99.8 & 99.8 \\
\hline
\end{tabular}

\subsection{Respiratory Functions}

LPS treatment significantly reduced the frequency, minute ventilation and relaxation time and increased tidal volume, time of inspiration and expiration, as well as peak expiratory 
flow $24 \mathrm{~h}$ after administration, whereas it did not alter peak inspiratory flow (Figure 1A-H, Figures S1 and S2). Penh correlating with airway hyperresponsiveness was remarkably increased already at baseline measurement and was further aggravated upon carbachol inhalation-induced bronchoconstriction in LPS-treated mice. $\mathrm{CO}$ and $\mathrm{TO}$ inhalation significantly reduced the carbachol-induced hyperresponsiveness in LPS-treated mice compared to paraffin oil (PO) inhalation used as a negative control, whereas LO significantly deteriorated baseline Penh (Figure 1I and Figure S1). Regarding the other basal respiratory parameters, tidal volume was significantly reduced by LO compared to the PO-treated LPS-administered group, but this seemingly ameliorating effect could be the result of the lowest frequency and minute ventilation measured in all groups.

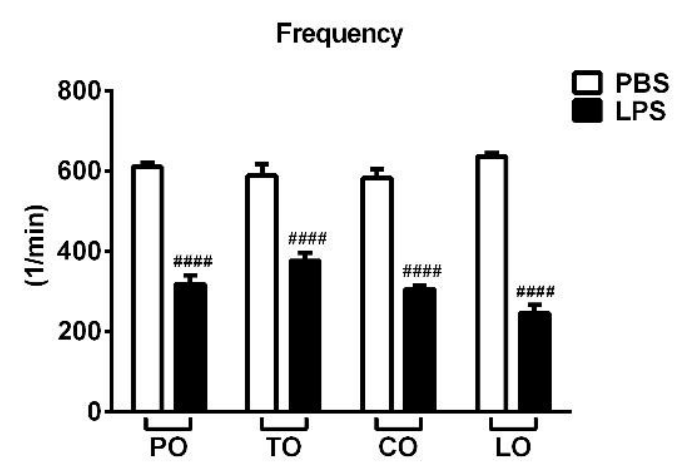

(A)

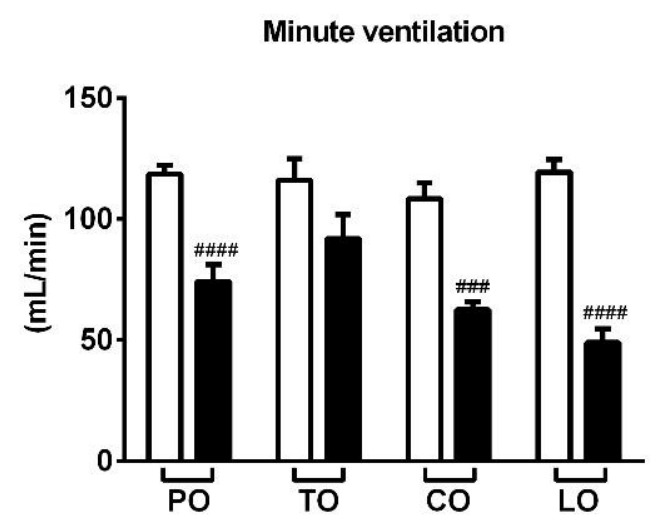

(C)

Time of expiration

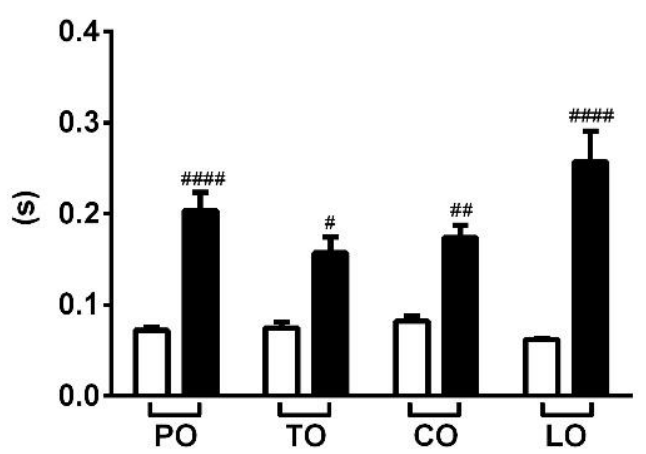

(E)
Tidal volume

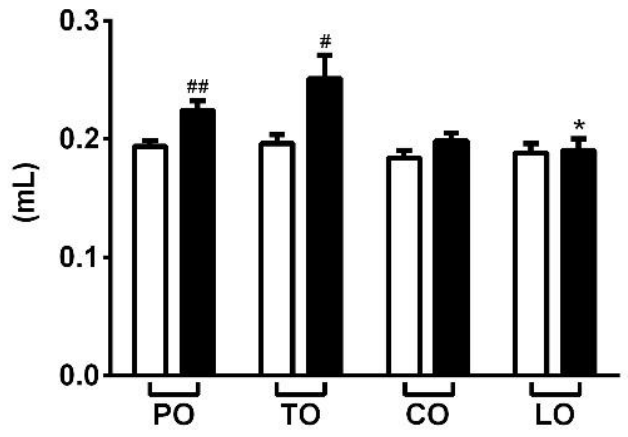

(B)

Time of inspiration

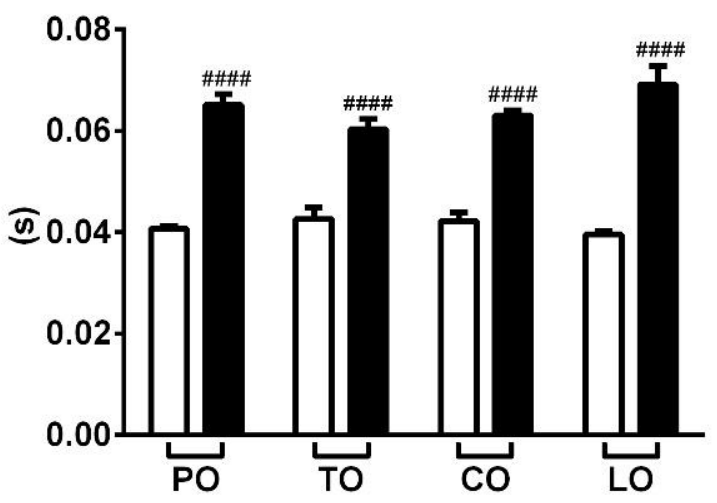

(D)

Peak inspiratory flow

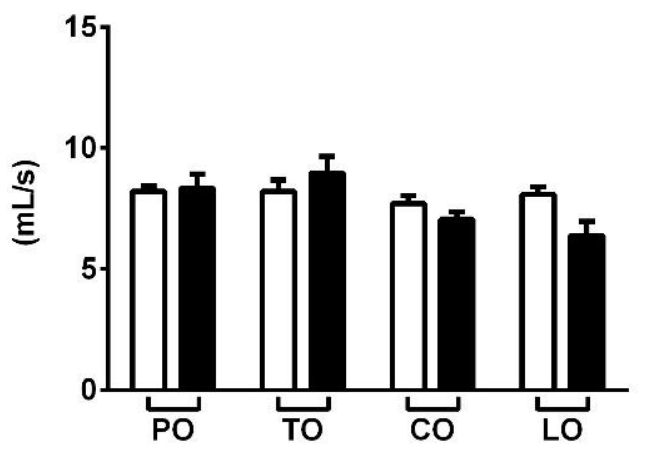

(F)

Figure 1. Cont. 
Peak expiratory flow

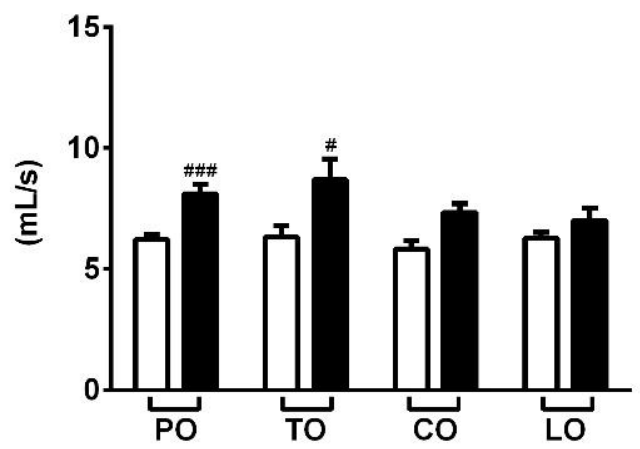

(G)

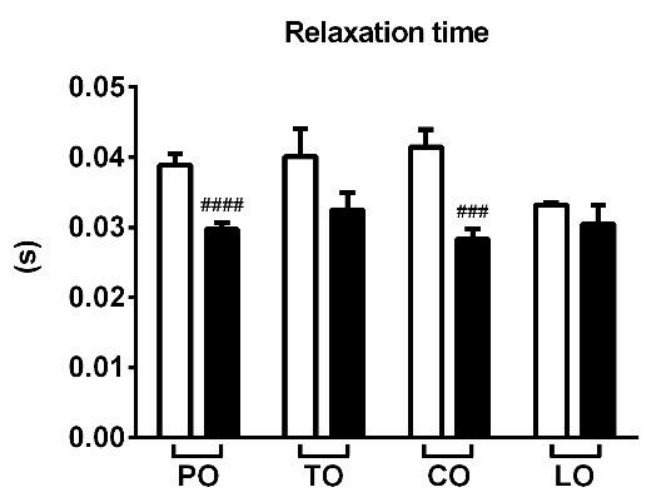

(H)

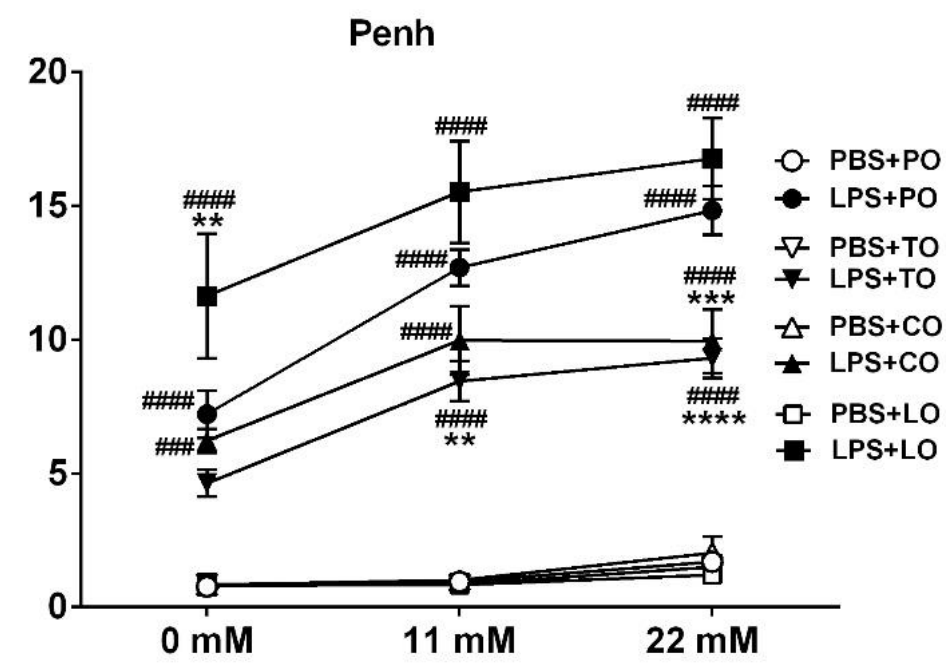

(I)

Figure 1. Effects of thyme (TO), cinnamon (CO) and lemongrass (LO) essential oils on (A) breathing frequency, (B) tidal volume, (C) minute ventilation, (D) time of inspiration, (E) time of expiration, (F) peak inspiratory flow, $(\mathbf{G})$ peak expiratory flow, $(\mathbf{H})$ relaxation time and (I) Penh compared to the negative control paraffin oil (PO), after lipopolysaccharide (LPS - black columns)/phosphate-buffered saline (PBS - white columns) treatment. ( $n=8-10 /$ group, \# $p<0.05$, \#\# $p<0.005$, \#\#\# $p<0.0005$, \#\#\#\# $p<0.0001$ vs. respective PBS-treated group, ${ }^{*} p<0.05,{ }^{* *} p<0.005,{ }^{* * *} p<0.0005,{ }^{* * * *} p<0.0001$ vs. LPS-PO-treated mice).

\subsection{Lung Histopathological Evaluation}

LPS administration induced a massive inflammatory infiltration in the lung composed of neutrophil granulocytes and macrophages associated with a remarkable perivascular and peribronchial edema formation (Figure 2). LPS-induced edema formation was decreased by TO, which was not significantly increased compared to its respective phosphate-buffered saline (PBS)-treated control. Regarding macrophage infiltration and total score, neither TO nor $\mathrm{CO}$ were significantly increased compared to their PBS-treated controls. LO did not influence the extent of histopathological alterations (Figure 3), although we found mild goblet cell hyperplasia, similarly to the LPS-treated group, and focal lymphocyte follicles after LO inhalation (data not shown). 


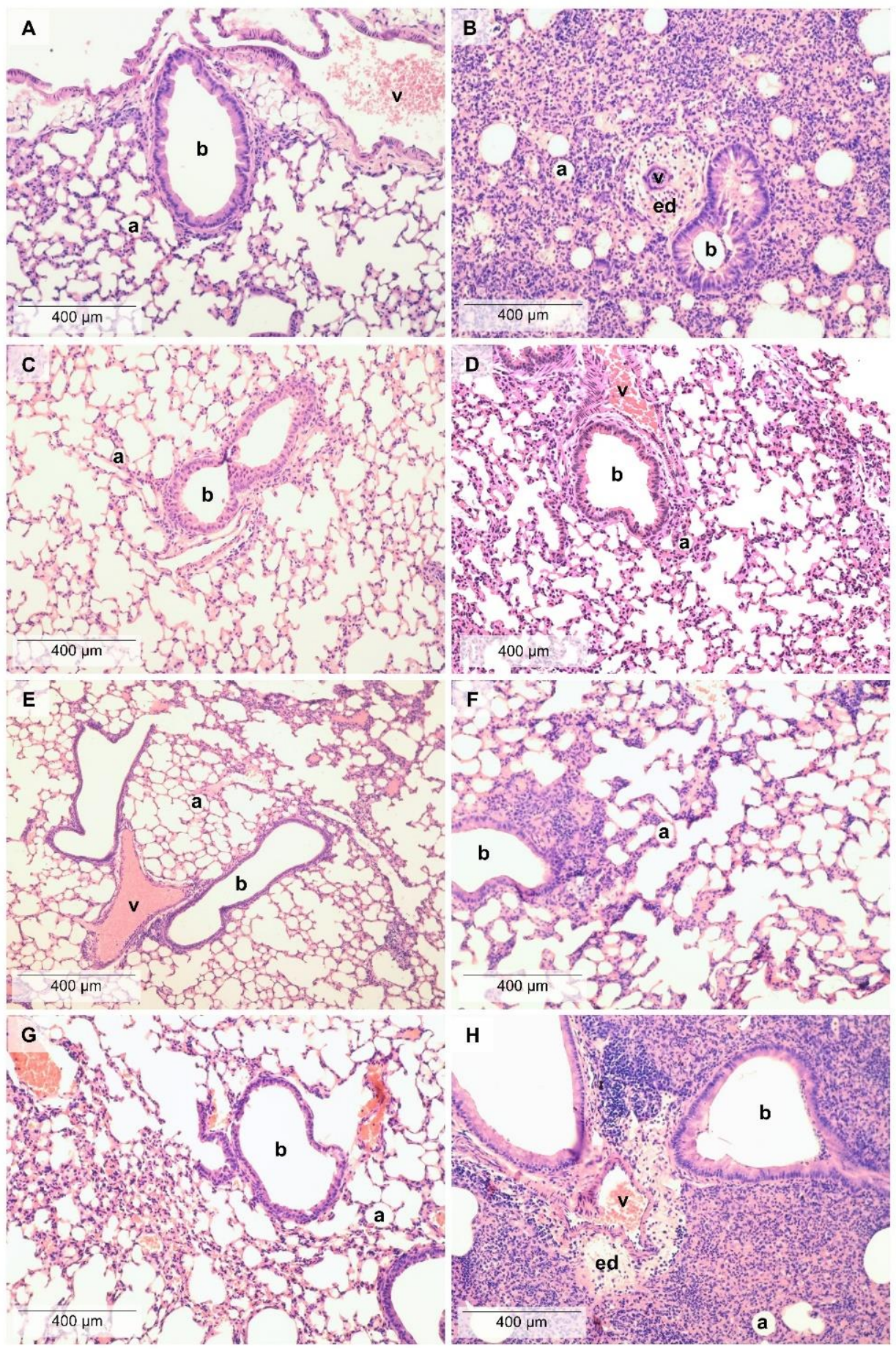

Figure 2. Histopathological alterations in the lung. Representative pictures of lung parenchyma after (A) PBS and PO treatment, (B) LPS and PO treatment, (C) PBS and TO treatment, (D) LPS and TO treatment, (E) PBS and CO treatment, (F) LPS and CO treatment, (G) PBS and LO treatment, and (H) LPS and LO treatment. (Hematoxylin-eosin staining, $200 \times$ magnification; a: alveolus, b: bronchiole, v: vessel, ed: edema). 


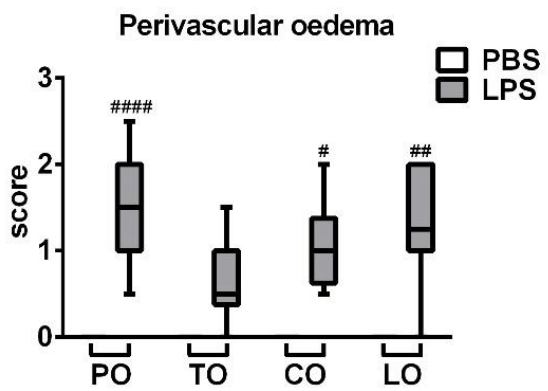

(A)

Macrophages

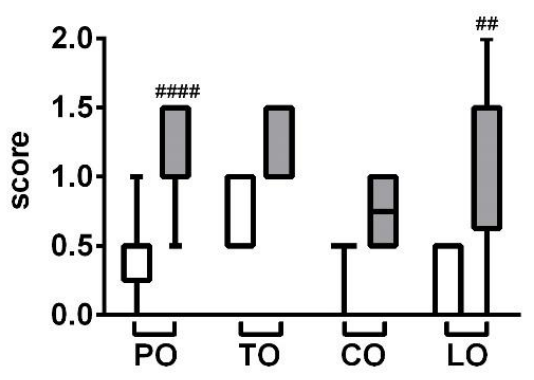

(C)

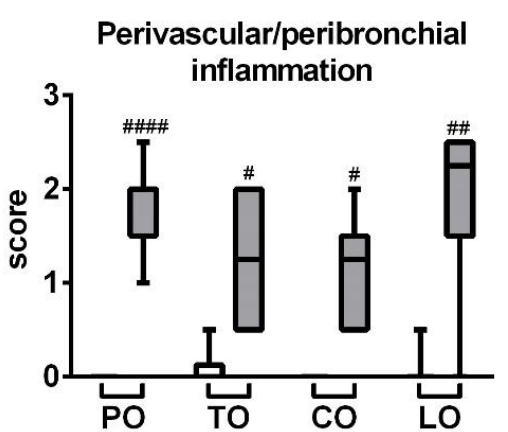

(B)

Total score

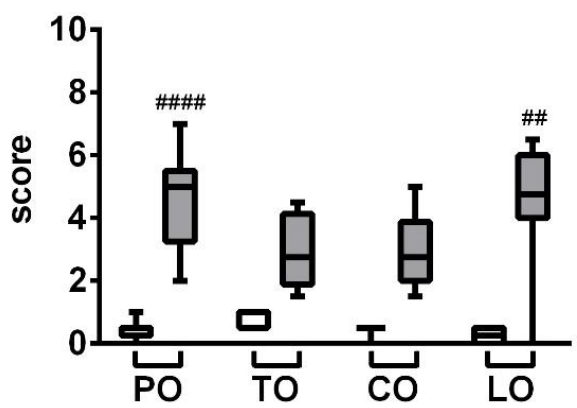

(D)

Figure 3. Semiquantitative evaluation of (A) perivascular and peribronchial edema, (B) accumulation of neutrophil granulocytes, (C) macrophages and (D) total score of lung histopathological alterations ( $n=8$-10/group, \# $p<0.05$, \#\# $p<0.005$, \#\#\# $p<0.000$ vs. respective PBS-treated group) are demonstrated in box plots showing the median, upper/lower quartile, and maximum/minimum values.

\subsection{Myeloperoxidase (MPO) Activity}

MPO activity-correlating with the number of activated granulocytes and macrophages-significantly increased after LPS treatment in the lung homogenates in accordance with the histopathological findings. TO decreased but, surprisingly, LO inhalation further increased enzyme activity in the LPS-treated animals, while CO had no significant effect on this parameter (Figure 4).

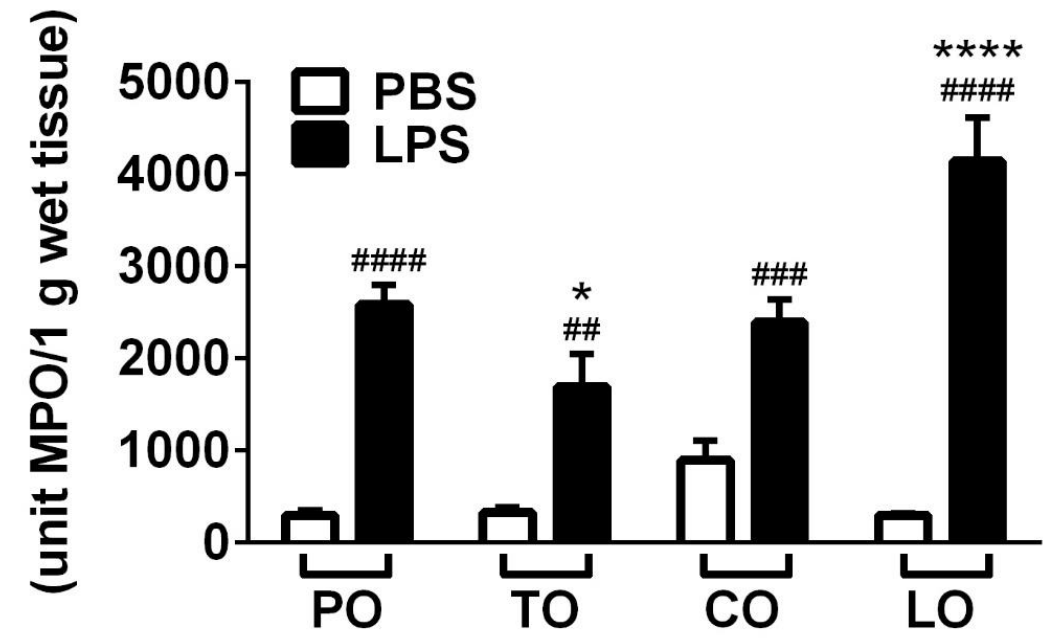

Figure 4. Results of myeloperoxidase (MPO) activity measurements. ( $n=8-10 /$ group, \#\# $p<0.005$, \#\#\# $p<0.0005$, \#\#\#\# $p<0.0001$ vs. respective PBS-treated group, ${ }^{*} p<0.05,{ }^{* * * *} p<0.0001$ vs. LPS-PO-treated). 


\section{Discussion}

We provide here the first evidence that TO (with thymol and $p$-cymene as main compounds) and CO (with cinnamaldehyde as main component) inhalation decrease inflammatory airway hyperresponsiveness and histopathological alterations in the endotoxin-induced pneumonitis mouse model. Furthermore, TO, but not $\mathrm{CO}$, decreases MPO activity, as a parameter of inflammatory cell activation as well. In contrast, LO (with citronellal and geraniol as main components) aggravates airway responsiveness and MPO activity.

These findings are supported by earlier data showing the anti-inflammatory potential of TO with different compositions in other airway inflammation models. Thyme and ivy extracts significantly reversed leukocyte infiltration in a similar LPS-induced acute lung inflammation rat model [23]. In an ovalbumin-induced chronic asthma mouse model thymol exerted a significant anti-inflammatory effect by inhibiting inflammatory cell accumulation and reducing pro-inflammatory cytokine concentrations, as well as ameliorating airway hyperresponsiveness and histopathological alterations in the lungs [12]. In a carrageenan-induced pleurisy rat model TO (with carvacrol as main component) and carvacrol, but not thymol reduced leukocyte migration. However, both thymol and carvacrol had a potent anti-edema effect [9]. We also found that TO significantly reduced edema formation, but not inflammatory cell infiltration. This virtually contradictory result could be explained by the different composition of TO used in our study with thymol and $p$-cymene as main components and only $3.2 \%$ carvacrol content. Recent data demonstrated the anti-inflammatory effect of $p$-cymene as well, significantly alleviating LPS-induced acute lung inflammation, edema, TNF- $\alpha$, IL- $1 \beta$ and IL-6 production $[10,11]$.

There is abundant literature on the anti-inflammatory effect of cinnamaldehyde, the main component of $\mathrm{CO}$, but these studies did not investigate functional parameters. It has been described that cinnamaldehyde inhibits the IL- $1 \beta$ and TNF- $\alpha$ production of macrophages stimulated by LPS in vitro [7], as well as in systemic inflammatory response syndrome in vivo [14]. The EO of Rimulus cinnamon or Guizhi (75.26\% cinnamaldehyde) also decreased IL-1 $\beta$, IL-18, IL-5, IF- $\gamma$, MCP-1, CSF-1 and MIP- $1 \beta$ in the serum, neutrophil cell count and nitric oxide production in the lung after intraperitoneal LPS administration [24].

LO with citral as main constituent has been described to suppress neutrophil adhesion and activation [25], edema formation and histopathological changes, as well as pro-inflammatory cytokine levels [13]. The anti-inflammatory property of citral is also supported by its ability to suppress LPS-induced cyclooxygenase-2 expression in the human macrophage-like U937 cell line [26]. In another in vitro study with macrophages LO pre-treatment in low doses significantly elevated IL-6 and IL-1 $\beta$ production; moreover, LO was only able to inhibit LPS effect in high doses. However, its main component, citral, effectively reduced cytokine levels both in pre-treatment and after LPS activation. These findings highlight the anti-inflammatory effect of the citral component of LO [8]. LO used in this study contained low levels of citral (neral + geranial), which can explain our results not supporting these earlier findings. However, much fewer data are available regarding the Cymbopogon nardus oil used in our study with citronellal and geraniol as main components. The EO of Citrus maxima (syn. Citrus grandis, contains citronellal and citronellol) and citronellal have been described to inhibit 5-lipoxygenase activity [27]. Geraniol, the other main component of LO used in our study, reduced MPO activity and pro-inflammatory cytokines production in vivo in an LPS-evoked acute lung injury model [15]. Moreover, geraniol dramatically reduced the expression of Toll-like receptor 4 and prevented nuclear factor $-\kappa \mathrm{B}$ activation [15]. Our contradictory findings might also be due to the different EO composition. Limonene, for instance, a minor component in Cymbopogon nardus was used in our study and has been described to induce bronchoconstriction in mice [28], which could explain the increased hyperresponsiveness elicited by our EO.

Therefore, when using the complex EOs instead of the individual components, the composition can significantly influence their biological effects and all components can interact with each other. For instance, 1,8-cineol, the minor TO and CO component, has some bronchodilator effects in 
guinea-pigs and rats $[29,30]$, which can contribute to the improvement of respiratory parameters. The anti-inflammatory effect (steroid-sparing effect) and mucolytic potential of 1,8-cineol have also been proven in humans [31]. Myrtol, a standardized mixture of EOs containing cineole, limonene (minor components of CO and LO) and $\alpha$-pinene (minor component of TO and CO) inhibited LPS-induced neutrophil accumulation, TNF- $\alpha$, IL-6 and MPO activity increase in mice [32]. Furthermore, linalool, the minor component of TO and $\mathrm{CO}$, attenuated histopathological changes and cytokine production in a similar model [21].

Airway inflammation is commonly accompanied by bacterial infections, therefore, the antibacterial and antifungal effects of EOs can also be beneficial in these conditions, particularly considering the spread of multiresistant bacteria and fungi [33-37]. We previously demonstrated the bactericidal effects of the vapor phase of TO, CO and LO, similarly to clove and eucalyptus EOs; as well as the bacteriostatic properties of Scots pine and peppermint $\mathrm{EO}$ against bacteria most common in respiratory infections including Staphylococcus aureus, methicillin-resistant S. aureus (MRSA) and Pseudomonas aeruginosa [38].

Despite the fact that our results provide useful information regarding the potential benefits and risks of EO inhalation in airway inflammation, a limitation of our experimental design is that we could not measure the exact EO concentration in the inhalation box but could only calculate its maximum value.

Considering the well-documented agonistic effects of thymol, cinnamaldehyde, carvacrol and linalool on members of the Transient Receptor Potential (TRP) ion channel family [39,40], the effects of these compounds might potentially be mediated by the Vanilloid 1 (TRPV1) or Ankyrin 1 (TRPA1) ion channels. TRPA1 and TRPV1 are expressed and often co-localized on the capsaicin-sensitive peptidergic afferents densely innervating the lung [41], as well as on pulmonary epithelial cells lymphocytes and bronchial smooth muscle cells [42,43]. TRPA1 and TRPV1 have been reported to be protective against the LPS-induced acute lung injury model [44-46]. The potential interactions of these essential oil components with the TRP ion channels in the LPS-induced acute lung injury model might open future drug developmental perspectives worth investigating.

\section{Materials and Methods}

\subsection{EO Samples and the Gas Chromatographic Analysis of Their Composition}

Cinnamon bark (Cinnamomum zeylanicum Nees. syn. Cinnamomum verum J.Presl), thyme (Thymus vulgaris L.), and lemongrass (Cymbopogon nardus (L.) Rendle) essential oils were bought from Aromax Ltd. (Budapest, Hungary). Gas chromatography-mass spectrometry (GC-MS, Agilent 6890 N/5973 N GC-MSD, Santa Clara, CA, USA) was used to analyze the chemical composition of the EO samples. The percentage composition of the EOs was evaluated with a flame ionization detector (FID). Compounds were identified based on retention times and spectral data of standard compounds, and the NIST 05 mass spectral library was also applied as previously described [38,47].

\subsection{Animals}

In the animal experiments, 10-18 week old female C57BL/6J mice [22] were used weighing $20.8 \pm 0.26 \mathrm{~g}$ (Mean \pm SEM) at the beginning of the experiment (Table S1). In order to avoid age-related differences, the age distribution of the mice was similar in each group. They were bred and kept in the Laboratory Animal House of the Department of Pharmacology and Pharmacotherapy at the University of Pécs. Optimal parameters were provided for all the animals (e.g., $325 \times 170 \times 140 \mathrm{~mm}$ cages, $12 \mathrm{~h}$ light/dark cycle, $24-25^{\circ} \mathrm{C}$, mouse chow, water).

During the experiments, the following regulations were taken into account: European legislation (Directive 2010/63/EU) and Hungarian Government regulation (40/2013., II. 14.) on the protection of animals used for scientific purposes, and the recommendations of the International Association for the Study of Pain. The study design was approved by the Ethics Committee on Animal Research of the University of Pécs (license No.: BA02/2000-26/2018, 21 June 2018). 


\subsection{Induction of Acute Airway Inflammation and Groups of Animals}

Animals received Escherichia coli (serotype: 083) LPS intratracheal (i.t.) (100 $\mu \mathrm{g}$ LPS dissolved in $60 \mu \mathrm{L}$ phosphate-buffered saline (PBS)) to induce acute airway inflammation. The endotoxin was isolated and purified in the Department of Microbiology, University of Pécs. During the administration of LPS, the animals were put under ketamine (100 mg/kg i.p.) and xylazine (5 mg/kg i.p.) anesthesia. Control mice received the same volume of sterile PBS [25]. Animals were treated with EO inhalation $1 \mathrm{~h}$ prior to and 4 and $23 \mathrm{~h}$ following LPS/PBS administration. Paraffin oil (PO) was used as negative control. Two oil drops $(0.05 \mathrm{~mL})$ were applied to a filter paper taped to the top of a box $(33.5 \times 19 \times 12 \mathrm{~cm})$ where mice were placed during the 30-min-long inhalation periods. The maximum concentration of the EOs was calculated as $6.55 \mu \mathrm{L} / \mathrm{L}$. Mice were randomized into eight groups: (1) the control group treated with PBS i.t. and PO inhalation, (2) mice treated with LPS i.t. and PO inhalation, (3) PBS i.t. and TO inhalation, (4) LPS i.t. and TO inhalation, (5) PBS i.t. and CO inhalation, (6) LPS i.t. and CO inhalation, (7) PBS i.t. and LO inhalation, and (8) LPS i.t. and LO inhalation ( $n=8-10 /$ group).

\subsection{Pulmonary Function Measurement}

Respiratory functions were determined by unrestrained whole-body plethysmography (WBP) (PLY3211, Buxco Europe Ltd., Winchester, UK) in conscious and spontaneously breathing animals $24 \mathrm{~h}$ after PBS/LPS administration [48]. Baseline measurements were registered for 5 min with aerosolized saline to determine the respiratory parameters, such as breathing frequency, tidal volume, minute ventilation, time of inspiration and expiration, peak inspiratory and expiratory flow, and relaxation time after 2 min of acclimation period. Enhanced pause (Penh), a calculated parameter ((expiratory time/relaxation time)/(max. expiratory flow/max. inspiratory flow)) correlating with airway hyperresponsiveness [48] was measured for 15-15 min after bronchoconstriction evoked by increasing concentrations (11 and $22 \mathrm{~mm}$ ) of aerosolized carbachol (carbamyl choline; Sigma, St. Louis, MO, USA; dissolved in saline, $50 \mu \mathrm{L}$ per mouse). Airway function parameters were registered every $10 \mathrm{~s}$ and averaged by the BioSystem XA Software for Windows (Buxco Research Systems, Wilmington, NC, USA).

\subsection{Histopathological Assessment and Semiquantitative Scoring}

Mice were anaesthetized, and their lungs were harvested after airway function measurements. Left lungs were fixed in $4 \%$ formaldehyde, embedded in paraffin, sectioned with a microtome (5-7 $\mu \mathrm{m})$, and stained with hematoxylin-eosin, as well as periodic acid-Schiff reaction for the visualization of the mucus-producing goblet cells. Inflammatory alterations were assessed by an expert pathologist in a blinded manner with semiquantitative histopathological scoring. Scoring parameters included the extent of perivascular edema (0-3), perivascular/peribronchial neutrophil accumulation (0-3), infiltration of activated macrophages/mononuclear cells in the alveolar spaces (0-2), and goblet cell hyperplasia of the bronchioles (0-2), as previously described [49,50]. A total inflammatory score was also assessed ranging between 0 and 10 by adding the subscores of the individual histopathological parameters.

\subsection{Spectrophotometric Measurement of Myeloperoxidase (MPO) Activity}

The activity of MPO enzyme correlates with the inflammatory infiltration of neutrophils and macrophages and this biochemical marker refers to the inflammation. Spectrophotometric measurement was made from the lung homogenates using $\mathrm{H}_{2} \mathrm{O}_{2}-3,3^{\prime}, 5,5^{\prime}$-tetramethylbenzidine $\left(\mathrm{TMB} / \mathrm{H}_{2} \mathrm{O}_{2}\right)$, and the MPO activity was compared to a human standard MPO preparation as described earlier [48]. All reagents were obtained from Sigma-Aldrich Ltd. (St. Louis, MO, USA). 


\subsection{Statistical Analysis of Data}

Respiratory parameters and MPO activity are expressed as mean \pm SEM and analyzed with one-way ANOVA followed by Tukey post-test. Penh was analyzed with two-way ANOVA followed by Tukey post-test. Composite histopathological inflammatory score values were evaluated by Kruskal-Wallis analysis followed by Dunn's post-test. In all cases, $p<0.05$ was accepted as significant. Statistical analysis was performed in GraphPad Prism v6 software.

\section{Conclusions}

We conclude that the LPS-induced acute lung inflammation mouse model is an appropriate mechanism model to investigate the effect of EO inhalation. TO and CO can be considered as potential adjuvant treatment in airway inflammation, but the Ceylon type of LO use should be avoided.

Supplementary Materials: The Supplementary Materials are available online. Figure S1: Percentage changes of respiratory parameters measured by unrestrained whole body plethysmography, Figure S2: Tidal volume and minute ventilation normalized to body weight, Table S1: Body weights of the mice.

Author Contributions: Conceptualization, Z.H. and G.H.; methodology, E.C., K.C., A.R.A., Á.K., L.K., B.K., and A.B.; formal analysis, E.C., K.C., and Á.K.; investigation, E.C., K.C., A.R.A., Á.K., L.K., and A.B.; resources, K.C., Á.K., Z.H., and G.H.; writing-original draft preparation, E.C. and K.C.; writing-review and editing, Z.H. and G.H.; visualization, E.C. and K.C.; supervision, Z.H. and G.H.; funding acquisition, K.C., Á.K., Z.H., and G.H. All authors have read and agreed to the published version of the manuscript.

Funding: Z.H. and K.C. were supported by the EFOP-3.6.2-16-2017-00008, and GINOP-2.3.2 STAY ALIVE. K.C. was also supported by the New National Excellence Program of the Ministry of Human Capacities ÚNKP-19-3-III-PTE-211. We hereby state that no financial or other relationships exist which might lead to conflicts of interest. Á. Kemény was supported by the János Bolyai Research Scholarship of the Hungarian Academy of Sciences.

Conflicts of Interest: The authors declare no conflict of interest. The funders had no role in the design of the study; in the collection, analyses, or interpretation of data; in the writing of the manuscript, or in the decision to publish the results.

\section{References}

1. WHO. The Top 10 Causes of Death. Available online: https://www.who.int/en/news-room/fact-sheets/detail/ the-top-10-causes-of-death (accessed on 16 July 2020).

2. Baser, K.H.C.; Buchbauer, G. Handbook of Essential Oils: Science, Technology, and Application; CRC Press (Taylor \& Francis Group): Boca Raton, FL, USA, 2010.

3. Faleiro, M.L.; Miguel, M.G. Use of essential oils and their components again multidrug-resistant bacteria. In Fighting Multidrug Resistance with Herbal Extracts, Essential Oils and their Components; Rai, M.K., Kon, K.V., Eds.; Elsevier: San Diego, CA, USA, 2013.

4. Jäger, W.; Nasel, B.; Nasel, C.; Binder, R.; Stimpfi, T.; Vycudilik, W.; Bucbauer, G. Pharmacokinetic studies of the fragrance compound 1, 8-cineol in humans during inhalation. Chem. Senses 1996, 21, 477-480. [CrossRef] [PubMed]

5. Horváth Gy Ács, K. Essential oils in the treatment of respiratory tract diseases highlighting their role in bacterial infections and their anti-inflammatory action: A review. Flavour Fragr. J. 2015, 30, 331-341. [CrossRef] [PubMed]

6. Kenia, P.; Houghton, T.; Beardsmore, C. Does inhaling menthol affect nasal patency or cough? Pediatr. Pulmonol. 2008, 43, 532-537. [CrossRef]

7. Kim, B.H.; Lee, Y.G.; Lee, J.; Lee, J.Y.; Cho, J.Y. Regulatory effect of cinnamaldehyde on monocyte/macrophage-mediated inflammatory responses. Mediators Inflamm. 2010, 2010, 529359. [CrossRef] [PubMed]

8. Bachiega, T.F.; Sforcin, J.M. Lemongrass and citral effect on cytokines production by murine macrophages. J. Ethnopharmacol. 2011, 137, 909-913. [CrossRef] 
9. Fachini-Queiroz, F.C.; Kummer, R.; Estevao-Silva, C.F.; de Barros Carvalho, M.D.; Cunha, J.M.; Grespan, R.; Bersani-Amado, C.A.; Cuman RK, N. Effects of thymol and carvacrol, constituents of Thymus vulgaris L. essential oil, on the inflammatory response. Evid.-Based Complement. Alternat. Med. 2012, 2012, 657026. [CrossRef]

10. Chen, L.; Zhao, L.; Zhang, C.; Lan, Z. Protective effect of p-cymene on lipopolysaccharide-induced acute lung injury in mice. Inflammation 2014, 37, 358-364. [CrossRef]

11. Zhong, W.; Chi, G.; Jiang, L.; Soromou, L.W.; Chen, N.; Hou, M.; Guo, W.; Deng, X.; Feng, H. p-Cymene modulates in vitro and in vivo cytokine production by inhibiting MAPK and NF- $\mathrm{KB}$ activation. Inflammation 2013, 36, 529-537. [CrossRef]

12. Zhou, E.; Fu, Y.; Wei, Z.; Yu, Y.; Zhang, X.; Yang, Z. Thymol attenuates allergic airway inflammation in ovalbumin (OVA)-induced mouse asthma. Fitoterapia 2014, 96, 131-137. [CrossRef]

13. Shen, Y.; Sun, Z.; Gua, X. Citral inhibits lipopolysaccharide-induced acute lung injury by activating PPAR- $\gamma$. Eur. J. Pharmacol. 2015, 747, 45-51. [CrossRef]

14. Mendes, S.J.F.; Sousa, F.I.A.B.; Pereira, D.M.S.; Ferro, T.A.F.; Pereira, I.C.P.; Silva, B.L.R.; Pinheriro, A.J.M.C.R.; Mouchrek, A.Q.S.; Monteiro-Neto, V.; Costa, S.K.P.; et al. Cinnamaldehyde modulates LPS-induced systemic inflammatory response syndrome through TRPA1-dependent and independent mechanisms. Int. Immunopharmacol. 2016, 34, 60-70. [CrossRef] [PubMed]

15. Jiang, K.; Zhang, T.; Yin, N.; Ma, X.; Zhao, G.; Wu, H.; Qiu, C.; Deng, G. Geraniol alleviates LPS-induced acute lung injury in mice via inhibiting inflammation and apoptosis. Oncotarget 2017, 8, 71038-71053. [CrossRef] [PubMed]

16. Salehi, B.; Mishra, A.P.; Shukla, I.; Sharifi-Rad, M.; del Mar Conteras, M.; Segura-Carretero, A.; Fathi, H.; Nasrabadi, N.N.; Kobarrfard, F.; Sharifi-Rad, J. Thymol, thyme, and other plant sources: Health and potential uses. Phytother. Res. 2018, 32, 1688-1706. [CrossRef] [PubMed]

17. Satyal, P.; Murray, B.L.; McFeeters, R.L.; Setzer, W.N. Essential oil characterization of Thymus vulgaris from various geographical locations. Foods 2016, 5, 70. [CrossRef] [PubMed]

18. ESCOP. ESCOP Monographs-The Scientific Foundation for Herbal Medicinal Products; European Scientific Cooperative on Phytotherapy: Stuttgart, Germany, 2003; pp. 92-97.

19. Clement, Y.N.; Baksh-Comeau, Y.S.; Seaforth, C.E. An ethnobotanical survey of medicinal plants in Trinidad. J. Ethnobiol. Ethnomed. 2015, 11, 67. [CrossRef] [PubMed]

20. Suroowan, S.; Mahomoodally, M.F. A comparative ethnopharmacological analysis of traditional medicine used against respiratory tract diseases in Mauritius. J. Ethnopharmacol. 2015, 177, 61-80. [CrossRef]

21. Huo, M.; Cui, X.; Xue, J.; Chi, G.; Gao, R.; Deng, X.; Guan, S.; Wei, J.; Soromou, L.W.; Feng, H.; et al. Anti-inflammatory effects of linalool in RAW 264.7 macrophages and lipopolysaccharide-induced lung injury model. J. Surg. Res. 2012, 180, E47-E54. [CrossRef]

22. Helyes, Z.; Hajna, Z. Endotoxin-induced airway inflammation and asthma models. In TRP Channels in Drug Discovery; Methods in Pharmacology and Toxicology; Szállási, Á., Bíró, T., Eds.; Springer Sciences+Business Media: Berlin, Germany, 2012; pp. 301-342.

23. Seibel, J.; Pergola, C.; Werz, O.; Kryshen, K.; Wosikowski, K.; Lehner, M.D.; Haunschild, J. Bronchipret ${ }^{\circledR}$ syrup containing thyme and ivy extracts suppresses bronchoalveolar inflammation and goblet cell hyperplasia in experimental bronchoalveolitis. Phytomedicine 2015, 22, 1172-1177. [CrossRef]

24. Rao, Z.; Xu, F.; Wen, T.; Wang, F.; Sang, W.; Zeng, N. Protective effects of essential oils from Rimulus cinnamon on endotoxin poisoning mice. Biomed. Pharmacother. 2018, 101, 304-310. [CrossRef]

25. Abe, S.; Maruyama, N.; Hayama, K.; Ishibashi, H.; Inoue, S.; Oshima, H.; Yamaguchi, H. Suppression of tumor necrosis factor-alpha-induced neutrophil adherence responses by essential oils. Mediat. Inflamm. 2003, 12, 323-328. [CrossRef]

26. Katsukawa, M.; Nakata, R.; Takizawa, Y.; Hori, K.; Takashi, S.; Inoue, H. Citral, a component of lemongrass oil, activates PPAR $\alpha$ and $\gamma$ and suppresses COX-2 expression. Biochim. Biophys. Acta 2010, 1801, 1214-1220. [CrossRef] [PubMed]

27. Tsai, M.L.; Lin, C.D.; Khoo, K.A.; Wang, M.Y.; Kuan, T.K.; Lin, W.C.; Zhang, Y.N.; Wang, Y.Y. Composition and bioactivity of essential oil from Citrus grandis (L.) Osbeck 'Mato Peiyu' leaf. Molecules 2017, 22, 2154. [CrossRef] [PubMed] 
28. Larsen, S.T.; Hougaard, K.S.; Hammer, M.; Alarie, Y.; Wolkoff, P.; Clausen, P.A.; Wilkins, C.K.; Nielsen, G.D. Effects of R-(+)- and S-(-)-limonene on the respiratory tract in mice. Hum. Exp. Toxicol. 2000, 19, 457-466. [CrossRef] [PubMed]

29. Bastos, V.P.D.; Brito, T.S.; Lima, F.J.B.; Pinho, J.P.M.; Lahlou, S.; Matos, F.J.A.; Santos, A.A.; Magalhaes, P.J.C. Inhibitory effect of 1,8-cineole on guinea-pig airway challenged with ovalbumin involves a preferential action on electromechanical coupling. Clin. Exp. Pharmacol. Physiol. 2009, 36, 1120-1126. [CrossRef]

30. Nascimento, N.R.F.; Refosco, R.M.D.C.; Vasconcelos, E.C.F.; Kerntopf, M.R.; Santos, C.F.; Batista, F.J.A.; Sousa, C.M.D.; Fonteles, M.C. 1,8-Cineole induces relaxation in rat and guinea-pig airway smooth muscle. J. Pharm. Pharmacol. 2009, 61, 361-366. [CrossRef]

31. Juergens, U.R.; Dethlefsen, U.; Steinkamp, G.; Gillisen, A.; Repges, R.; Vetter, H. Anti-infammatory activity of1.8-cineol (eucalyptol) in bronchial asthma: A double-blind placebo-controlled trial. Respir. Med. 2003, 97, 250-256. [CrossRef]

32. Yu, P.J.; Wan, L.M.; Wan, S.H.; Chen, W.Y.; Xie, H.; Meng, D.M.; Zhang, J.J.; Xiao, X.L. Standardized myrtol attenuates lipopolysaccharide induced acute lung injury in mice. Pharm. Biol. 2016, 54, 3211-3216. [CrossRef]

33. Buru, A.S.; Pichika, M.R.; Neela, V.; Mohandas, K. In vitro antibacterial effects of Cinnamomum extracts on common bacteria found in wound infections with emphasis on methicillin-resistant Staphylococcus aureus. J. Ethnopharmacol. 2014, 153, 587-595. [CrossRef]

34. Burt, S. Essential oils: Antibacterial properties and potential applications in foods-a review. Int. J. Food Microbiol. 2004, 94, 223-253. [CrossRef]

35. Celik, A.; Aydinlik, N.; Arslan, I. Phytochemical constituents and inhibitory activity towards methicillin-resistant Staphylococcus aureus strains on Eryngium species (Apiaceae). Chem. Biodivers. 2011, 8, 454-459. [CrossRef]

36. Stamenic, M.; Vulic, J.; Dijlas, M.; Tadic, V.; Petrovic, S.; Zizovic, I. Free-radical scavenging activity and antibacterial impact of Greek oregano isolates obtained by SFE. Food Chem. 2014, 165, 307-315. [CrossRef] [PubMed]

37. Tripathi, P.; Dubey, N.K. Exploitation of natural products as an alternative strategy to control postharvest fungal rotting of fruit and vegetables. Postharvest Biol. Technol. 2004, 32, 235-245. [CrossRef]

38. Ács, K.; Bencsik, T.; Böszörményi, A.; Kocsis, B.; Horváth, G. Essential oils and their vapors as potential antibacterial agents against respiratory tract pathogens. Nat. Prod. Commun. 2016, 11, 1709-1712. [CrossRef] [PubMed]

39. Mihara, S.; Shibamoto, T. The role of flavor and fragrance chemicals in TRPA1 (transient receptor potential cation channel, member A1) activity associated with allergies. Allergy Asthma Clin. Immunol. 2015, 11, 11. [CrossRef]

40. Premkumar, L.S. Transient receptor potential channels as targets for phytochemicals. ACS Chem. Neurosci. 2014, 5, 1117-1130. [CrossRef]

41. Nassenstein, C.; Kwong, K.; Taylor-Clark, T.; Kollarik, M.; MacGlashan, D.M.; Braun, A.; Undem, B.J. Expression and function of the ion channel TRPA1 in vagal afferent nerves innervating mouse lungs. J. Physiol. 2008, 586, 1595-1604. [CrossRef]

42. McGarvey, L.P.; Butler, C.A.; Stokesberry, S.; Polley, L.; McQuaid, S.; Abdullah, H.; Ashraf, S.; McGahon, M.K.; Curtis, T.M.; Arron, J.; et al. Increased expression of bronchial epithelial transient receptor potential vanilloid 1 channels in patients with severe asthma. J. Allergy Clin. Immunol. 2014, 133, 704-712. [CrossRef]

43. Nassini, R.; Pedretti, P.; Moretto, N.; Fusi, C.; Carnini, C.; Facchinetti, F.; Viscomi, A.R.; Pisano, A.R.; Stokesberry, S.; Brunmark, C.; et al. Transient receptor potential ankyrin 1 channel localized to non-neuronal airway cells promotes non-neurogenic inflammation. PLOS ONE 2012, 7, e42454. [CrossRef]

44. Hajna, Z.; Csekő, K.; Kemény, Á.; Kereskai, L.; Kiss, T.; Perkecz, A.; Szitter, I.; Kocsis, B.; Pintér, E.; Helyes, Z. Complex regulatory role of the TRPA1 receptor in acute and chronic airway inflammation mouse models. Int. J. Mol. Sci. 2020, 21, 4109. [CrossRef]

45. Elekes, K.; Helyes, Z.; Németh, J.; Sándor, K.; Pozsgai, G.; Kereskai, L.; Börzsei, R.; Pintér, E.; Szabó, Á.; Szolcsányi, J. Role of capsaicin-sensitive afferents and sensory neuropeptides in endotoxin-induced airway inflammation and consequent bronchial hyperreactivity in the mouse. Regul. Pept. 2007, 141, 44-54. [CrossRef] 
46. Helyes, Z.; Elekes, K.; Németh, J.; Pozsgai, G.; Sándor, K.; Kereskai, L.; Börzsei, R.; Pintér, E.; Szab, Á.; Szolcsányi, J. Role of transient receptor potential vanilloid 1 receptors in endotoxin-induced airway inflammation in the mouse. Am. J. Physiol. Lung Cell. Mol. Physiol. 2007, 292, 1173-1181. [CrossRef] [PubMed]

47. Ács, K.; Balázs, V.L.; Kocsis, B.; Bencsik, T.; Böszörményi, A.; Horváth, G. Antibacterial activity evaluation of selected essential oils in liquid and vapor phase on respiratory tract pathogens. BMC Complement. Altern. Med. 2018, 18, 227. [CrossRef] [PubMed]

48. Helyes, Z.; Pintér, E.; Sándor, K.; Elekes, K.; Bánvölgyi, A.; Keszhelyi, D.; Szőke, E.; Tóth, D.M.; Sándor, Z.; Kereskai, L.; et al. Impaired defense mechanism against inflammation, hyperalgesia, and airway hyperreactivity in somatostatin 4 receptor gene-deleted mice. Proc. Nat. Acad. Sci. USA 2009, 106, 13088-13093. [CrossRef]

49. Helyes, Z.; Elekes, K.; Sándor, K.; Szitter, I.; Kereskai, I.; Pintér, E.; Kemény, Á.; Szolcsányi, J.; McLaughlin, L.; Vasiliou, S.; et al. Involvement of preprotachykinin A gene-encoded peptides and the neurokinin 1 receptor in endotoxin-induced murine airway inflammation. Neuropeptides 2010, 44, 399-406. [CrossRef] [PubMed]

50. Zeldin, D.C.; Wohlford-Lenane, C.; Chulada, P.; Bradbury, J.A.; Scarborough, P.E.; Roggli, V.; Langenbach, R.; Schwarz, D.A. Airway inflammation and responsiveness in prostaglandin H synthase-deficient mice exposed to bacterial lipopolysaccharide. Am. J. Respir. Cell Mol. Biol. 2001, 25, 457-465. [CrossRef] [PubMed]

Sample Availability: Samples of the compounds are not available from the authors. 